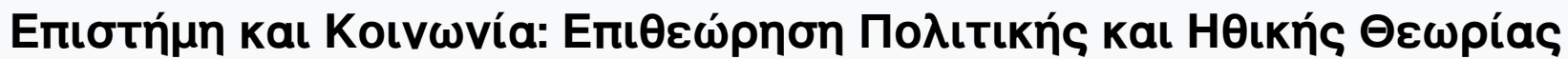

Tóp. 13 (2004)

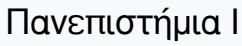

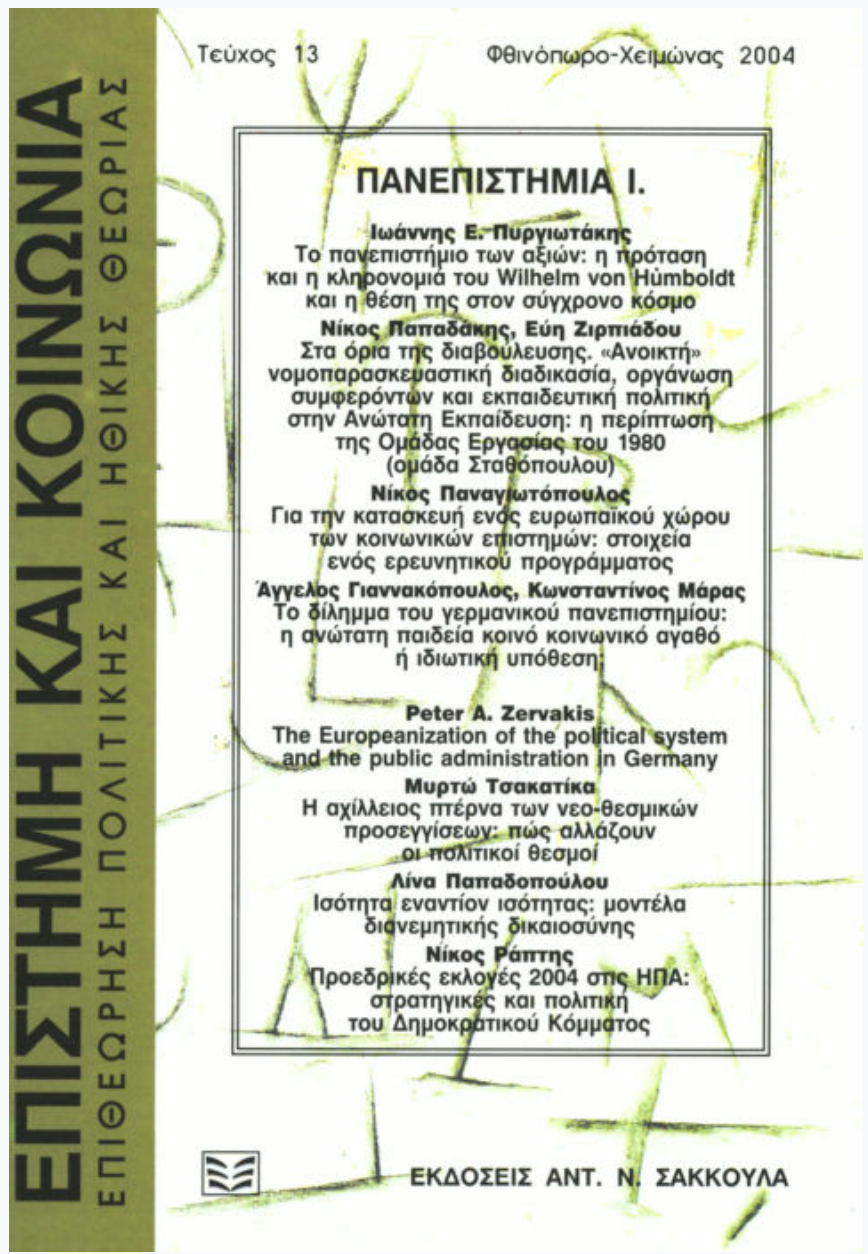

\section{Peter Singer, Rethinking Life and Death: The Collapse of our Traditional Ethics}

Milena Ivanova

doi: $10.12681 /$ sas.586

Copyright (C 2015, Milena Ivanova

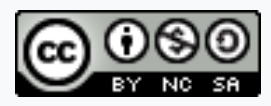

Aঠ¿ıа Xpńбnৎ Creative Commons Attribution-NonCommercial-ShareAlike 4.0.

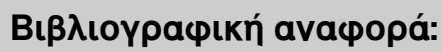

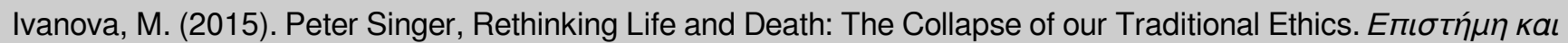

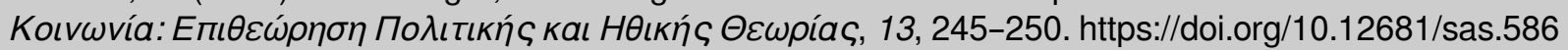


Peter Singer, Rethinking Life and Death: The Collapse of our Traditional

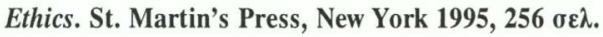

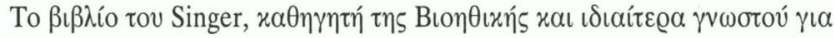

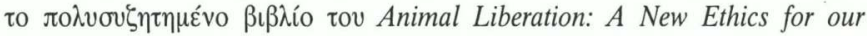

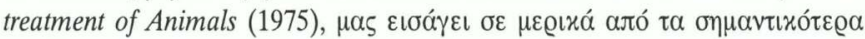

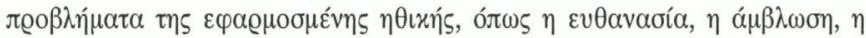

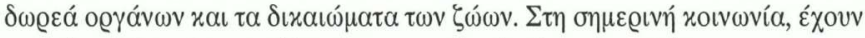

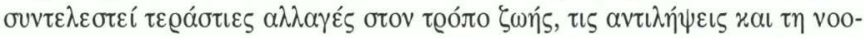

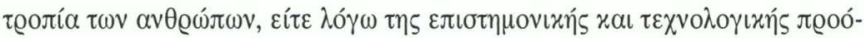

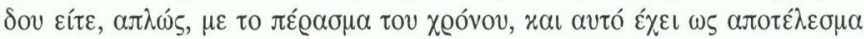

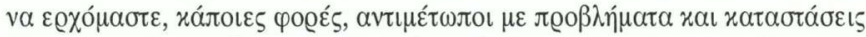

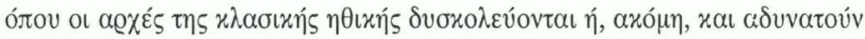

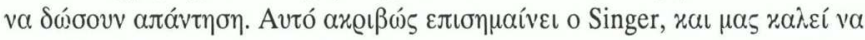

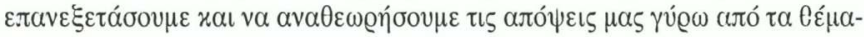

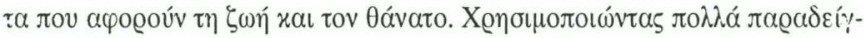

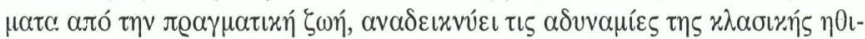

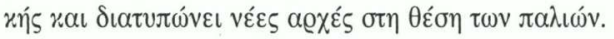

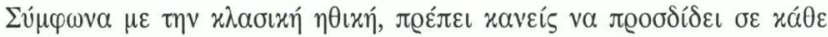

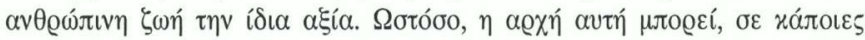

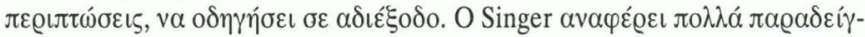

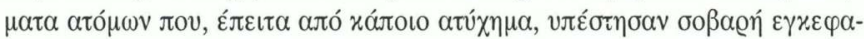

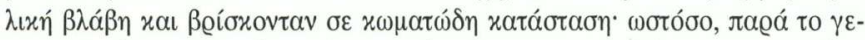

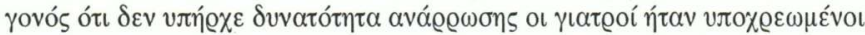

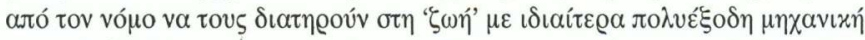

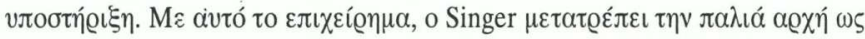

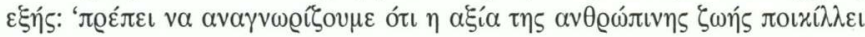

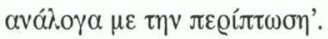

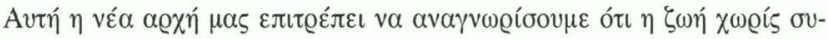

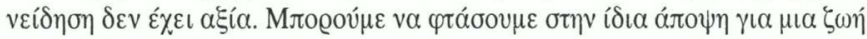

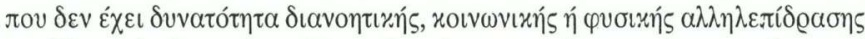

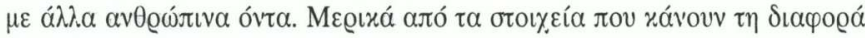

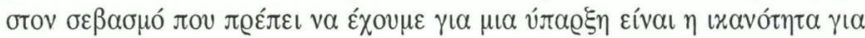

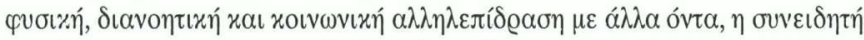

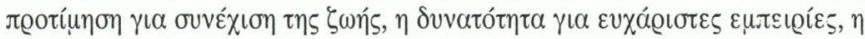

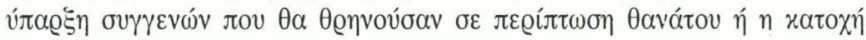




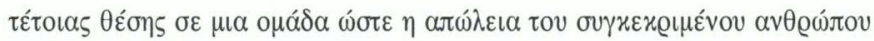

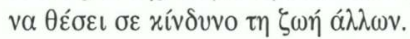

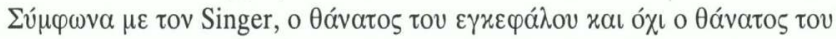

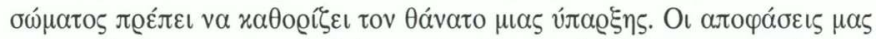

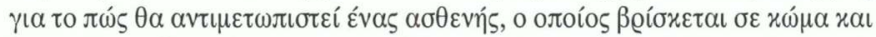

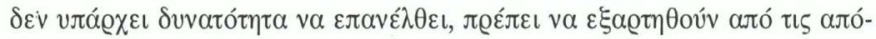

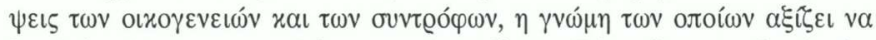

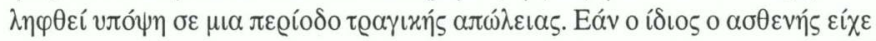

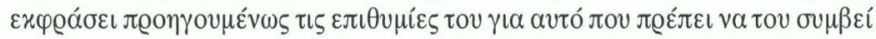

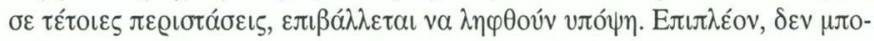

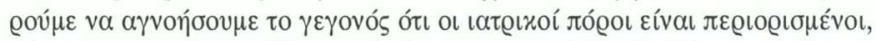

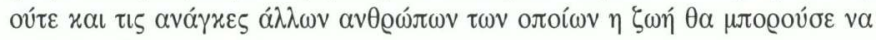

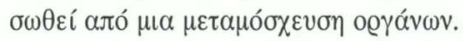

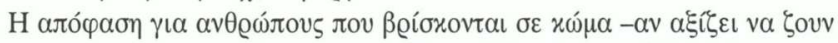

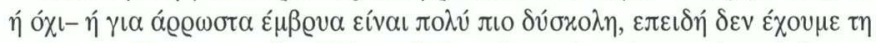

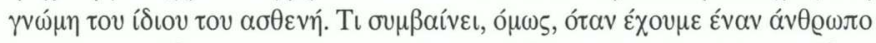

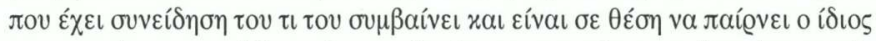

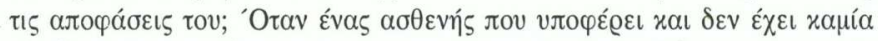

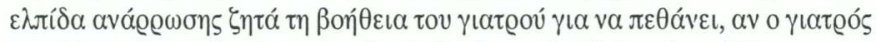

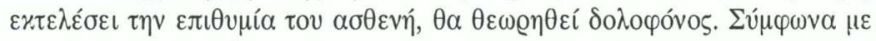

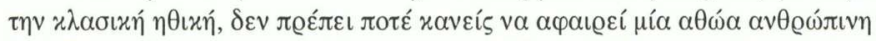

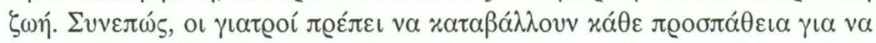

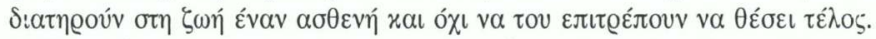

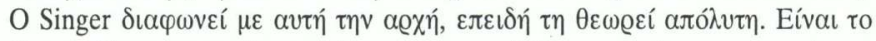

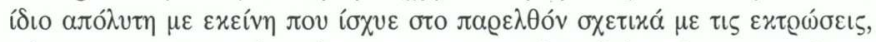

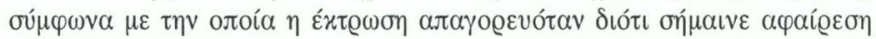

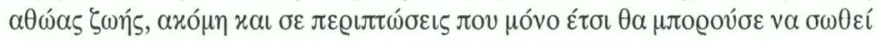

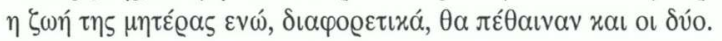

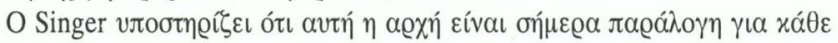

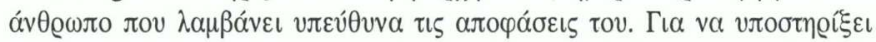

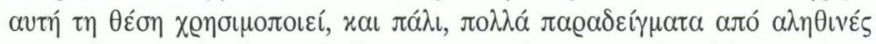

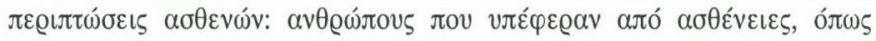

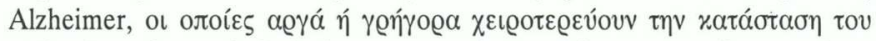

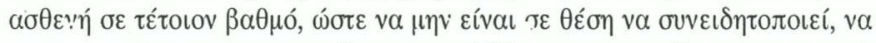

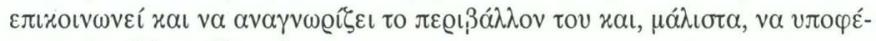

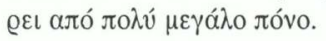

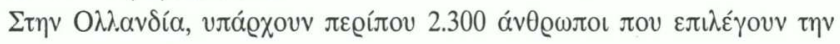




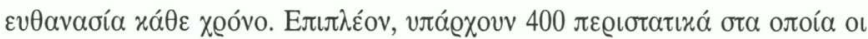

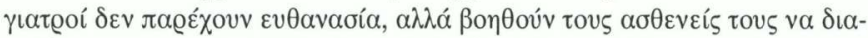

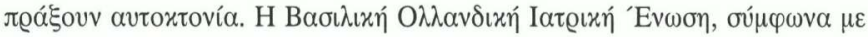

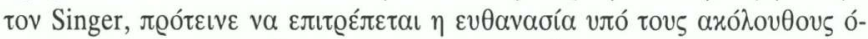

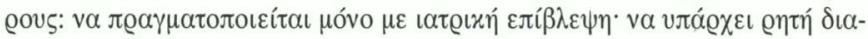

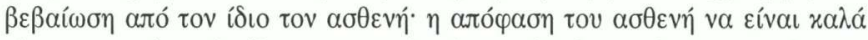

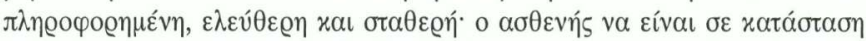

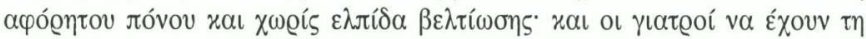

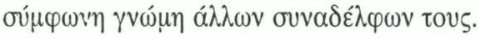

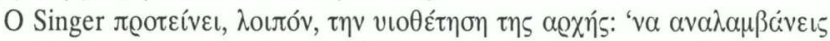

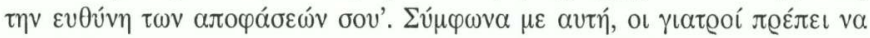

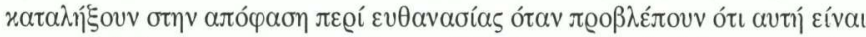

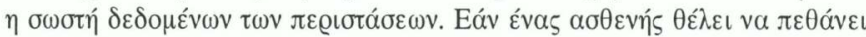

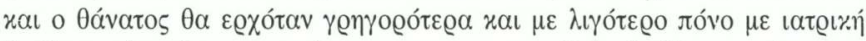

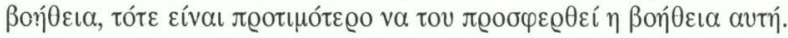

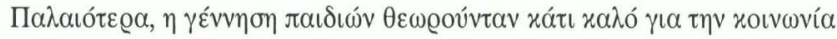

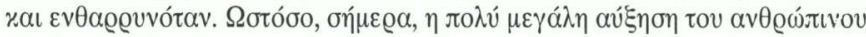

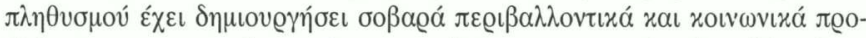

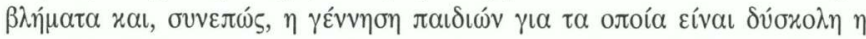

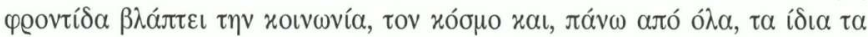

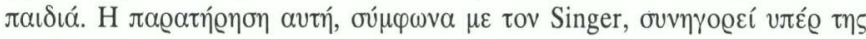

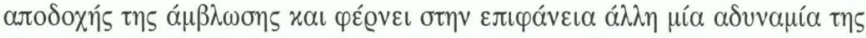

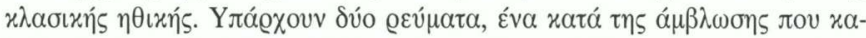

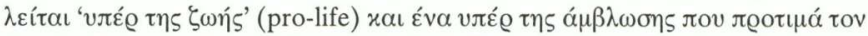

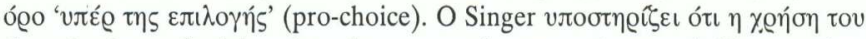

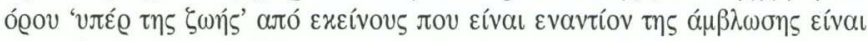

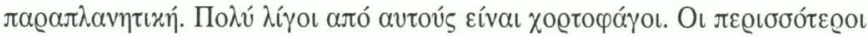

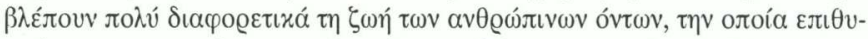

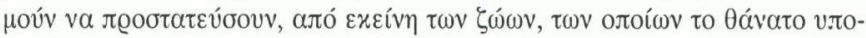

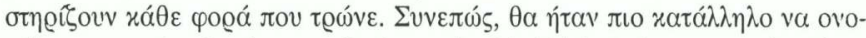

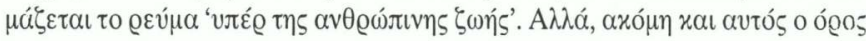

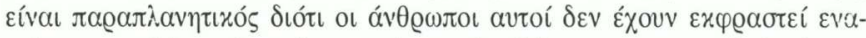

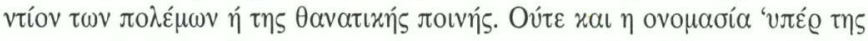

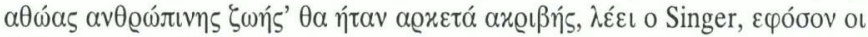

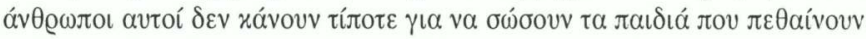

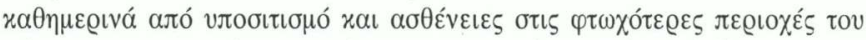

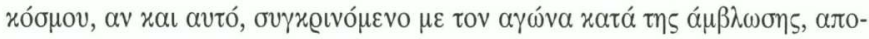




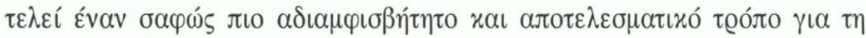

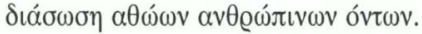

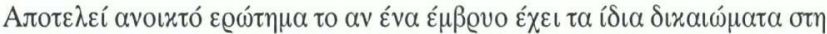

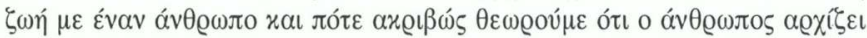

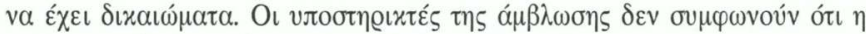

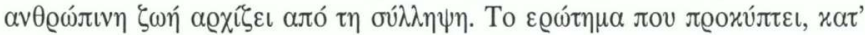

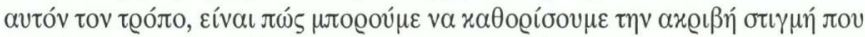

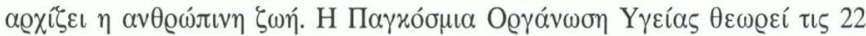

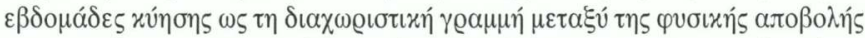

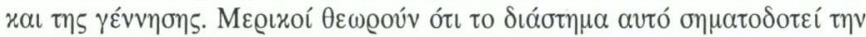

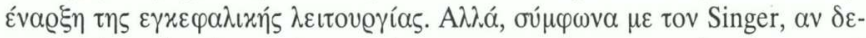

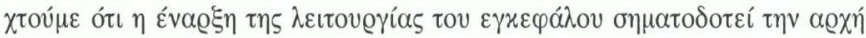

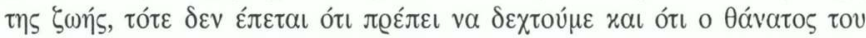

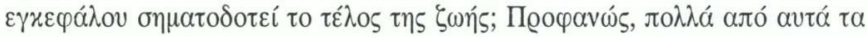

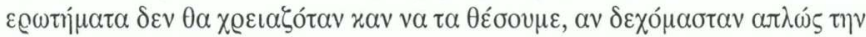

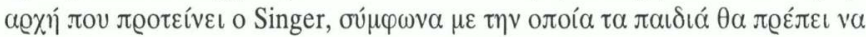

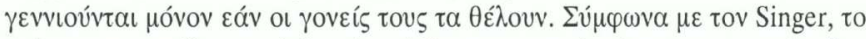

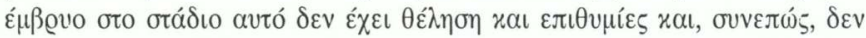

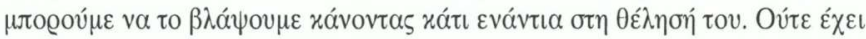

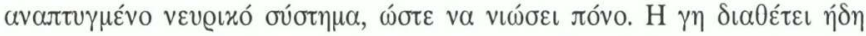

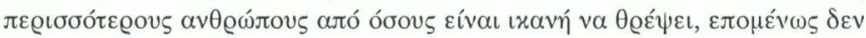

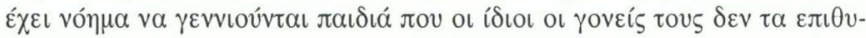

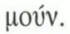

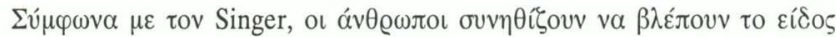

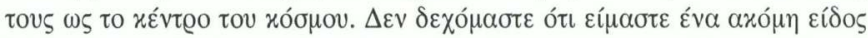

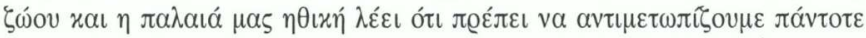

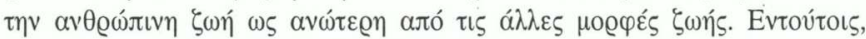

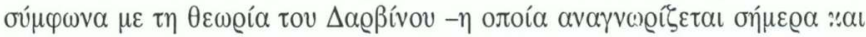

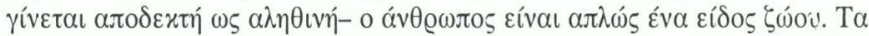

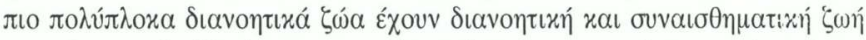

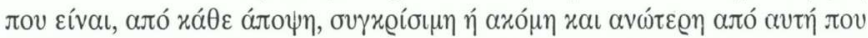

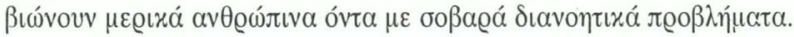

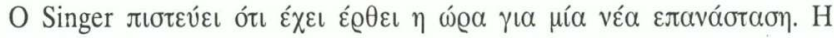

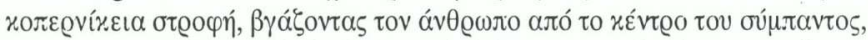

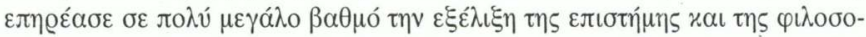

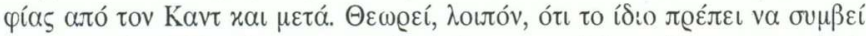

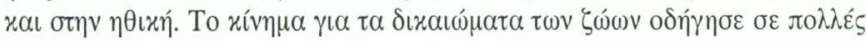




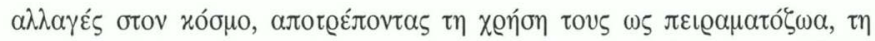

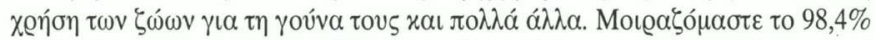

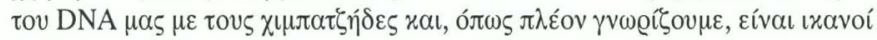

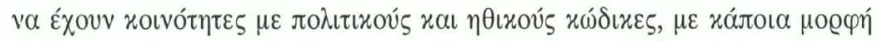

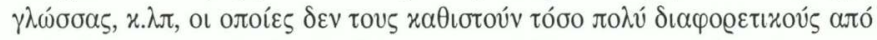

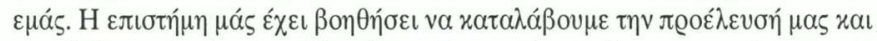

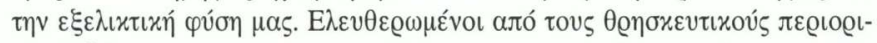

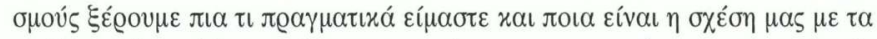

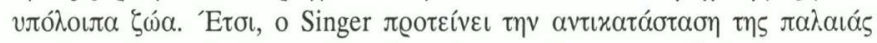

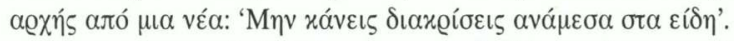

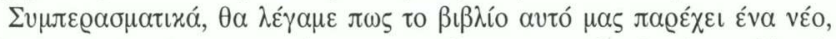

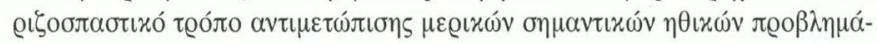

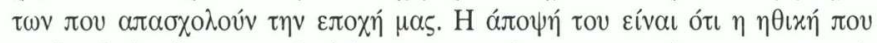

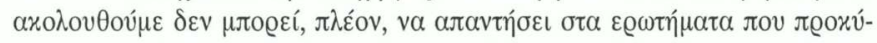

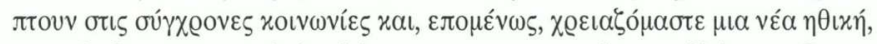

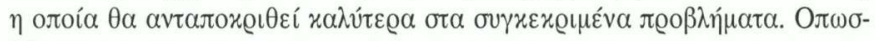

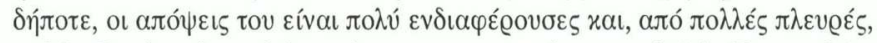

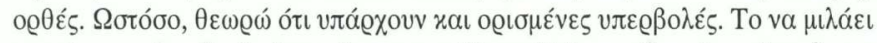

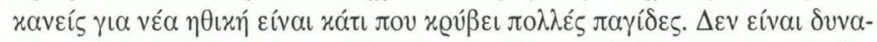

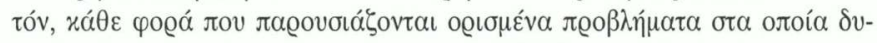

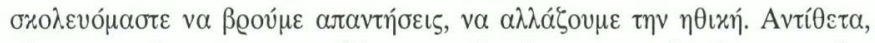

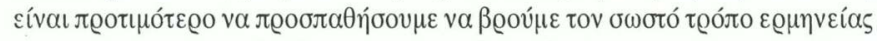

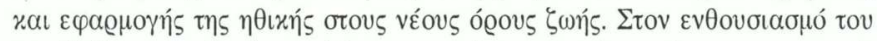

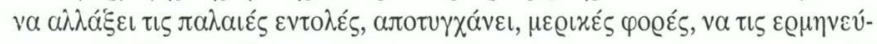

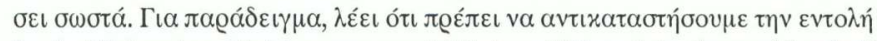

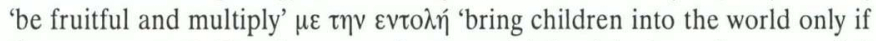

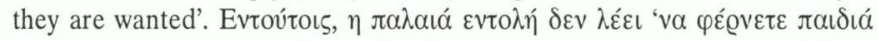

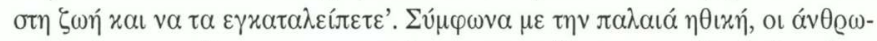

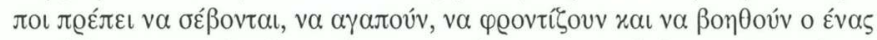

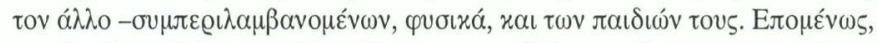

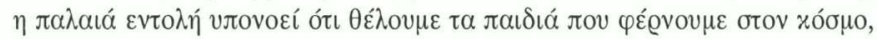

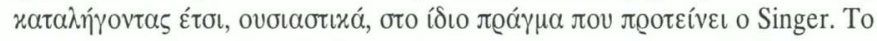

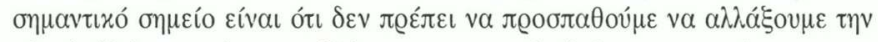

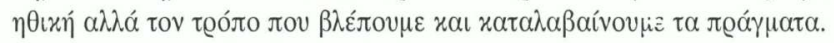

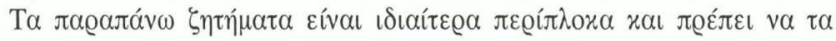

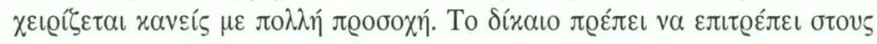

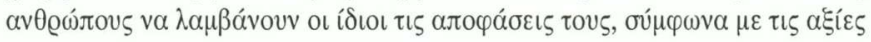




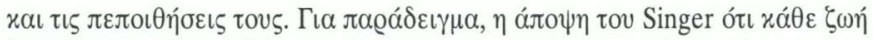

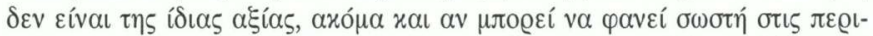

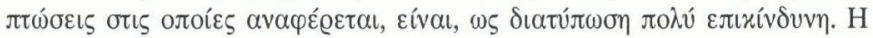

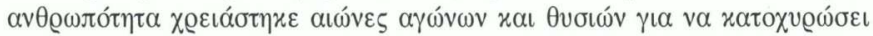

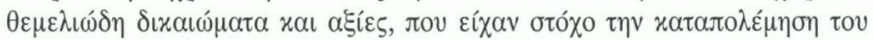

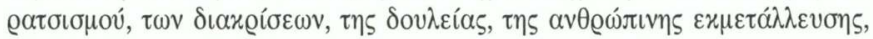

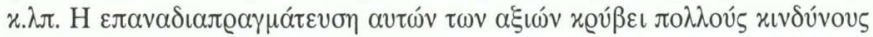

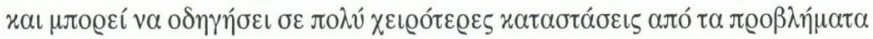

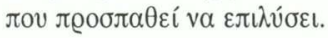

Milena Ivanova 